\title{
Clinical Outcomes After Bilateral Implantation of a Trifocal Presbyopia-Correcting Intraocular Lens in an Indian Population
}

This article was published in the following Dove Press journal: Clinical Ophthalmology

\author{
Dandapani Ramamurthy' \\ Abhay Vasavada ${ }^{2}$ \\ Prema Padmanabhan (iD ${ }^{3}$ \\ Jagadesh C Reddy ${ }^{4}$ \\ Naren Shetty ${ }^{5}$ \\ Arindam Dey ${ }^{6}$ \\ Rachapalle Reddi Sudhir $\mathbb{D}^{3}$ \\ 'The Eye Foundation, Coimbatore, Tamil \\ Nadu, India; ${ }^{2}$ Raghudeep Eye Hospital, \\ Ahmedabad, Gujarat, India; ${ }^{3}$ Medical \\ Research Foundation, Chennai, Tamil \\ Nadu, India; ${ }^{4}$ LV Prasad Eye Institute, \\ Hyderabad, Telangana, India; ${ }^{5}$ Narayana \\ Nethralaya Eye Hospital, Rajajinagar, \\ Bangalore, India; ${ }^{6}$ Alcon Laboratories \\ (India) Private Ltd, Bangalore, India
}

Purpose: To evaluate the effectiveness and safety of a presbyopia-correcting trifocal intraocular lens (IOL), AcrySof ${ }^{(\mathbb{B}}$ IQ PanOptix ${ }^{\circledR}$ (TFNT00), in an Indian population.

Patients and Methods: This prospective, multicenter, observational, single-arm, postmarketing study included 67 patients undergoing cataract surgery with bilateral implantation of TFNT00 across five Indian sites. Postoperative outcomes were assessed at 3 months after second eye surgery. Effectiveness outcomes included: mean binocular and monocular visual acuity (VA) at distance $(4 \mathrm{~m})$, intermediate $(60 \mathrm{~cm})$, and near $(40 \mathrm{~cm})$; binocular defocus curve; manifest refraction; and subjective symptom questionnaire evaluation. Safety outcomes included the rate of ocular adverse events and mesopic contrast sensitivity.

Results: Mean binocular and monocular distance-corrected and uncorrected VAs of 0.1 $\log$ MAR or better (approximately 20/25 Snellen) were achieved at distance, intermediate, and near. Overall, $\geq 70 \%$ of patients achieved binocular $0.1 \operatorname{logMAR}$ vision or better across all distances. TFNT00 maintained a mean VA of $0.1 \operatorname{logMAR}$ or better at the defocus range of +0.5 diopters (D) to $-2.5 \mathrm{D}(200 \mathrm{~cm}$ to $40 \mathrm{~cm})$. The subjective symptom questionnaireassessed frequency of halo visual disturbances was low at Month 3; halos were reported "none of the time" to "only some of the time" in $86.6 \%$ of patients. The large majority of patients $(98.5 \%)$ were "satisfied" or "very satisfied" with their near, intermediate, and distance vision at Month 3 , and $\geq 94.0 \%$ of patients reported spectacle independence for tasks at all distances. The adverse event rate was low; no patients discontinued due to an adverse event.

Conclusion: TFNT00 provided a continuous range of vision of 20/25 or better for distance to near and performed effectively at an intermediate functional distance of $60 \mathrm{~cm}$, resulting in high levels of spectacle independence and patient satisfaction. TFNT00 demonstrated a good safety profile and a low post-operative frequency of halo visual disturbances.

Keywords: PanOptix, multifocal, cataract surgery, non-apodized, intraocular lens, IOL

\section{Plain Language Summary}

Cataract surgery involves the surgical removal of the cloudy natural lens from an eye and its replacement with an artificial intraocular lens (IOL). In many cases, patients receive a monofocal IOL, which is primarily designed to correct distance vision, requiring them to use spectacles for near and intermediate vision correction. In contrast, trifocal IOLs, such as TFNT00, are designed to provide patients with a continuous range of vision, which reduces the need for spectacles. Unlike other trifocal IOLs that commonly target an intermediate focal point of $80 \mathrm{~cm}$, TFNT00 provides an intermediate focal point of $60 \mathrm{~cm}$. This aims to increase patient satisfaction by making intermediate vision more comfortable because most
Correspondence: Dandapani Ramamurthy The Eye Foundation, Diwan Bahadur Road, Coimbatore, Tamil Nadu 641002, India

Tel +9| 4224242000

Email drramamurthy@theeyefoundation. in 
intermediate distance work, such as computer use, is performed at 60 to $70 \mathrm{~cm}$ for the average person.

The purpose of this study was to evaluate TFNT00 in 67 Indian patients, namely for its efficacy in terms of visual outcomes and spectacle independence, and its safety. Our results show that at 3 months post-surgery, TFNT00 provided a functional continuous range of vision of 20/25 or better for farther (4 meters) to nearer $(40 \mathrm{~cm})$ distances, and performed effectively at an intermediate distance of $60 \mathrm{~cm}$. Most patients receiving TFNT00 did not require spectacles at 3 months after surgery. Additionally, TFNT00 demonstrated a good safety profile and the number of patients seeing bright rings around a light source (known as "halos") was low. This study provides the first clinical data on this lens in an Indian population.

\section{Introduction}

Visual demands have changed considerably over the last few decades, and patients today seek spectacle independence at all distances following cataract surgery and presbyopiacorrecting intraocular lens (IOL) implantation. Monofocal IOLs focus light on a single focal point providing distance vision but do not provide near and intermediate vision, ${ }^{1}$ thereby increasing spectacle dependency at these distances. $^{1-4}$ In contrast, multifocal IOLs are designed with refractive or diffractive optical properties that focus light at multiple foci, providing vision over a range of distances, $2,3,5-7$ thus multifocal IOLs provide greater spectacle independence than monofocal IOLs. ${ }^{2,3,7}$ However, these advances have often come at the cost of reduced contrast sensitivity or increased photic phenomena. ${ }^{1,2,4-6,8,9}$ Additionally, multifocal IOLs with only two focal points (bifocal) provide sub-optimal intermediate visual acuity (VA). ${ }^{10}$

Diffractive trifocal IOLs have been shown to provide functional distance, intermediate, and near vision, and are designed with three optical focal points. ${ }^{11,12}$ AcrySof $^{\circledR}$ IQ PanOptix $^{\circledR}$ presbyopia-correcting IOL model TFNT00 (Alcon Vision LLC) is a non-apodized, ultraviolet- and blue light-filtering, hydrophobic acrylic, diffractive IOL. ${ }^{13-15}$ TFNT00 comprises quadrifocal technology; however, in terms of function, it acts as a trifocal. ${ }^{13-15}$ The IOL uses a proprietary optical technology, ENLIGHTENTM, to manipulate the quadrifocal design and redistribute the incoming light from the focal point at $120 \mathrm{~cm}$ to the distance focal point. $^{14}$ This creates an enhanced distance add power, together with the intermediate +2.17 diopters $(\mathrm{D} ; 60 \mathrm{~cm})$ and $+3.25 \mathrm{D}$ near $(40 \mathrm{~cm})$ add powers, ${ }^{14-16}$ providing a continuous range of vision. The $4.5 \mathrm{~mm}$ non-apodized, diffractive zone allows high light utilization, transmitting
$88 \%$ of light to the retina at a $3.0 \mathrm{~mm}$ pupil size, $50 \%$ of which is allocated to distance, with $25 \%$ to intermediate and $25 \%$ to near; ${ }^{14,15,17}$ thus providing optimized performance in a wide range of lighting conditions due to low dependence on the pupil size. ${ }^{13,14}$ Patient demand for functional intermediate vision has grown with the rising popularity of handheld devices and increasing use of computers in daily life. Unlike other trifocal IOLs that commonly target an intermediate focal point of $80 \mathrm{~cm}$, the novel diffractive structure of TFNT00 provides an optimum intermediate focal point of $60 \mathrm{~cm}$ (arm's length). ${ }^{16,18}$ This design aims to increase patient satisfaction by making intermediate vision more comfortable, because most intermediate distance work is performed at 60 to $70 \mathrm{~cm}$ for the average person. ${ }^{19}$

The popularity of cataract surgery and IOL implantation has increased exponentially in India over the past two decades. $^{20-22}$ Demand for multifocal IOLs is expected to surge globally due to: the large number of cataract surgeries ( 26 million cataract surgeries performed in 2017); changing socioeconomic frameworks; the world's aging population; improvements in healthcare sectors and expenditure; increased demand for spectacle independence; access to innovative, advanced IOLs; and increased patient awareness. ${ }^{15}$ Although previous clinical investigations have demonstrated a continuous range of vision from near to distance with TFNT00, ${ }^{14,23-28}$ to date, no clinical studies have been conducted in Indian patients. The purpose of this study was to evaluate the 3-month postoperative effectiveness and safety of TFNT00 in providing a range of vision (distance, intermediate, and near) in an Indian population.

\section{Methods}

\section{Study Design}

This was a prospective, single-arm, multicenter, unmasked, observational cohort study to evaluate the effectiveness and safety of in-the-bag implantation of TFNT00 for the visual correction of aphakia in adult patients. The study was carried out between January 15, 2019, and January 18, 2020. The study was approved by the institutional ethics committees (The Eye Foundation, Iladevi Cataract \& IOL Research Center, Medical Research Foundation, LV Prasad Eye Institute and Narayana Nethralaya Eye Hospital), conducted in accordance with the Declaration of Helsinki and registered on ClinicalTrials.gov (NCT03706066). Written informed consent was obtained from all patients. Patients included in the study were $\geq 18$ years of age with bilateral cataracts, had an IOL power calculation of between +16.0 
and $+26.0 \mathrm{D}$, and preoperative regular keratometric astigmatism of $<1.0 \mathrm{D}$ in both eyes. Exclusion criteria included: clinically significant corneal abnormality, disease, or degeneration; history of, predisposition to, or concurrent retinal conditions; glaucoma; ocular trauma; patients with previous refractive surgery or corneal transplant; any ocular pathology, conditions, or degenerative disorders that could affect postoperative visual outcomes; and patients with rubella, congenital, traumatic, or complicated cataracts. IOL power was calculated using the Barrett Universal II formula $^{29}$ and an optical A-constant of 119.1.

\section{Study Procedures}

The first surgical eye was defined as the eye with the worse preoperative best-corrected distance VA (BCDVA). If the BCDVA was the same in both eyes, the right eye was the first surgical eye. The second eye implant occurred within 7-90 days of the first eye implant. Repeated screening of some parameters was conducted if patients had their second eye surgery $>40$ days after their initial screening prior to first eye implantation. A total of eight scheduled visits were planned: one pre-operative visit, two operative visits, and postoperative visits at Days 1-2 and Month 1 (after each surgery) and Month 3 (after second surgery).

VA assessments were performed under photopic conditions with chart background luminance of approximately $85 \mathrm{~cd} / \mathrm{m}^{2}$. Distance VA $(4 \mathrm{~m})$ and defocus were measured using CSV-1000 (Vector Vision Inc.) Charts 1, 2, and R; intermediate $(60 \mathrm{~cm})$ and near $(40 \mathrm{~cm})$ VA were measured using Early Treatment Diabetic Retinopathy Study Near Card Charts 1 and 2. For monocular assessments, the contralateral eye was occluded.

Binocular contrast sensitivity was measured using a CSV1000HGT contrast sensitivity unit (Vector Vision Inc.). For assessments under mesopic conditions, participants were fitted with neutral density filters to reduce their perception of the chart luminance to approximately $3 \mathrm{~cd} / \mathrm{m}^{2}$. Subjective posterior capsular opacification (PCO) was assessed during slit-lamp examination and, if present, clinically graded as nonsignificant, clinically significant, or clinically significant requiring neodymium-doped yttrium aluminum garnet (Nd:YAG) treatment. Adverse events (AEs) were coded using the Medical Dictionary for Regulatory Activities (MedDRA), version 20.0.

\section{Effectiveness and Safety Outcomes}

All primary and secondary outcomes were assessed at Month 3 after bilateral implantation. The primary effectiveness outcome was mean photopic binocular BCDVA $(4 \mathrm{~m})$.
Secondary effectiveness outcomes included mean photopic monocular BCDVA; mean photopic binocular and monocular distance-corrected VAs at intermediate and near (DCIVA [60 cm] and DCNVA [40 cm], respectively); mean photopic binocular and monocular uncorrected VAs at distance, intermediate, and near (UCDVA, UCIVA, and UCNVA, respectively); mean binocular defocus curve; manifest refraction; and subjective symptom questionnaire post-implantation. The safety outcomes were the rate of ocular AEs (including secondary surgical interventions [SSIs]), device deficiencies, subjective PCO assessment, posterior capsulotomy, and the mean binocular contrast sensitivity with and without glare for mesopic conditions.

\section{Patient-Reported Outcomes}

Patients were proactively asked to subjectively rate their quality of vision and experience of visual disturbances using a subjective symptom questionnaire developed by Alcon. This questionnaire consisted of 11 questions derived from the Spectacle Independence Lens Vision Evaluation and Repurchase (SILVER) ${ }^{30,31}$ and Assessment of Photic Phenomena and Lens EffectS (APPLES) ${ }^{31,32}$ questionnaires. The questions related to each patient's quality of vision according to their: satisfaction and need for spectacles for near, intermediate, and distance vision; frequency and severity of halos; difficulty driving at night; and overall cataract surgery satisfaction. Responses were reported on a 4- or 5-point categorical scale ranging from "very dissatisfied" to "very satisfied" for satisfaction items, from "none of the time" to "all of the time" for frequency items, and from "none" to "severe" for severity items.

\section{Sample Size Calculation}

There was no hypothesis testing in this study; therefore, the sample size chosen was not based on power calculations. The required sample size of 80 participants was determined based on a drop-out rate of $20 \%$. This sample was considered sufficient to ensure that at least 64 eligible participants completed the study. With 64 participants, a two-sided 95\% confidence interval for mean binocular BCDVA will extend 0.044 $\operatorname{logMAR}$ from the observed mean, assuming that the standard deviation (SD) is known to be $0.18 \log$ MAR (conservative estimate based on previous IOL studies ${ }^{33,34}$ ), and the confidence interval is based on the large sample $\mathrm{z}$ statistic.

\section{Statistical Methods}

The all-implanted analysis set (all eyes with successful implantation plus at least one postoperative visit) was the 
primary analysis set for all effectiveness endpoints, except defocus, and included all patients implanted. The safety analysis set (all eyes with attempted implantation) was the primary analysis set for all safety endpoints, except contrast sensitivity, and included all eyes that had attempted study IOL implantation (successful or aborted after contact with the eye). The best-case analysis set (all eyes successfully implanted with $\geq 1$ postoperative visit) was the primary analysis set for defocus and contrast sensitivity analyses. It included all eyes successfully implanted with the study IOL that had at least: one postoperative visit; no previous surgery for the correction of refractive errors; no preoperative ocular pathology or macular degeneration at any time; and no major protocol deviations. There was no hypothesis testing in this study; therefore, data were summarized using descriptive statistics.

\section{Results}

\section{Patient Disposition and Demographics}

A total of 80 participants were enrolled across five sites in India, of which 7 patients discontinued prior to IOL implantation (Figure 1). Of these, 68 eligible patients were successfully implanted bilaterally with TFNT00 and 5 patients were implanted unilaterally. Of the 68 patients who received TFNT00 implanted bilaterally, 1 discontinued from participation after implantation of the study IOLs and was considered lost to follow-up; therefore, 67 patients completed the study (Figure 1). Study patients were all of Indian race (Table 1). Their overall mean age was $58.5 \pm 11.46$ years; approximately two-thirds of patients were aged $<65$ years (65.8\%), and 53.4\% of patients were female (Table 1). Baseline characteristics were largely similar between first and second eyes; mean preoperative monocular BCDVA was $0.43 \log$ MAR for first eyes and $0.27 \log$ AAR for second eyes; mean pupil size ( $4 \mathrm{~mm}$ ), axial length, anterior chamber depth, corneal thickness, and lens thickness were also comparable between eyes (Table 1).

\section{Visual Outcomes}

Distance-Corrected and Uncorrected Visual Acuity

Patients achieved a mean \pm standard deviation binocular BCDVA of $<0.0 \quad \operatorname{logMAR}$ at Month $3(-0.052 \pm 0.09$ logMAR) (Table 2) and $92.5 \%$ of patients achieved a binocular BCDVA of $0.1 \log \mathrm{MAR}$ or better (Figure 2A). Binocular DCIVA and DCNVA of $<0.1$ logMAR were also achieved $(0.039 \pm 0.11$ and $0.061 \pm 0.11 \log$ MAR,

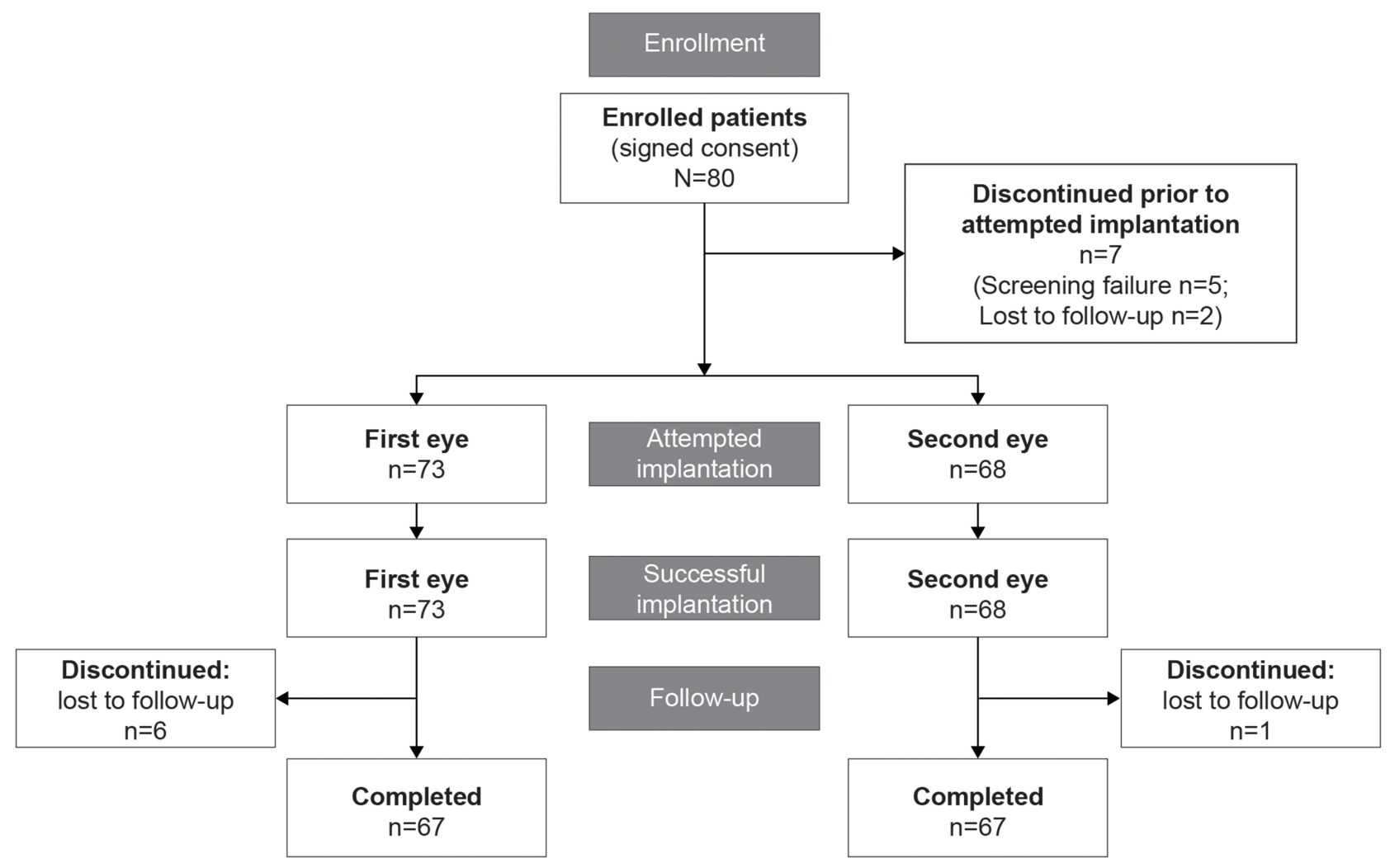

Figure I Patient disposition. 
Table I Baseline Demographics and Clinical Characteristics of Patient Study Population (All-Implanted Analysis Set)

\begin{tabular}{|c|c|c|}
\hline Parameters & \multicolumn{2}{|c|}{ TFNT00 ( $\mathbf{N}=73)$} \\
\hline Age, years, n (\%) & \\
\hline$<65$ & \multicolumn{2}{|l|}{$48(65.8)$} \\
\hline$\geq 65$ & \multicolumn{2}{|l|}{$25(34.2)$} \\
\hline Mean \pm SD & \multicolumn{2}{|l|}{$58.5 \pm 11.46$} \\
\hline Median & \multirow{2}{*}{\multicolumn{2}{|c|}{$\begin{array}{l}60 \\
(28,82)\end{array}$}} \\
\hline (minimum, maximum) & & \\
\hline Sex, n (\%) & \\
\hline Female & \multicolumn{2}{|l|}{$39(53.4)$} \\
\hline Male & \multicolumn{2}{|l|}{$34(46.6)$} \\
\hline Race, n (\%) & \multirow{2}{*}{\multicolumn{2}{|c|}{$73(100.0)$}} \\
\hline Asian (Indian) & & \\
\hline $\begin{array}{l}\text { Clinical Characteristics, } \\
\text { mean } \pm \text { SD }\end{array}$ & $\begin{array}{l}\text { First Eye } \\
(N=73)\end{array}$ & $\begin{array}{l}\text { Second Eye } \\
(N=68)\end{array}$ \\
\hline Monocular BCDVA (logMAR) & $0.43 \pm 0.267$ & $0.27 \pm 0.147$ \\
\hline Sphere (D) & $-0.87 \pm 2.430$ & $-0.32 \pm 1.937$ \\
\hline Cylinder (D) & $0.52 \pm 0.611$ & $0.40 \pm 0.403$ \\
\hline MRSE (D) & $-0.65 \pm 2.344$ & $-0.16 \pm 1.897$ \\
\hline Pupil size (mm) & $4.05 \pm 0.786$ & $4.08 \pm 0.832$ \\
\hline Axial length (mm) & $23.31 \pm 0.854$ & $23.27 \pm 0.857$ \\
\hline Anterior chamber depth (mm) & $3.29 \pm 0.331$ & $3.23 \pm 0.330$ \\
\hline Corneal thickness $(\mu \mathrm{m})$ & $525.4 \pm 30.66$ & $526.9 \pm 32.79$ \\
\hline Lens thickness (mm) & $4.16 \pm 0.416$ & $4.25 \pm 0.416$ \\
\hline
\end{tabular}

Note: Baseline refers to preoperative.

Abbreviations: BCDVA, best-corrected distance visual acuity; D, diopter; MRSE, manifest refraction spherical equivalent; $\mathrm{N}$, number of eyes in the treatment group; $\mathrm{SD}$, standard deviation.

respectively) (Table 2), with $84.8 \%$ and $78.8 \%$ of patients, respectively, achieving $0.1 \log$ MAR or better VA (Figure 2A).

Similar results were achieved for binocular uncorrected VA at Month 3; patients demonstrated a mean binocular UCDVA of $\leq 0.0 \operatorname{logMAR}(0.011 \pm 0.11 \log \mathrm{MAR})$ and a mean binocular UCIVA and UCNVA of $<0.1 \operatorname{logMAR}$ $(0.055 \pm 0.10$ and $0.092 \pm 0.13 \log$ MAR) (Table 2). Overall, $83.6 \%, 80.3 \%$, and $69.7 \%$ of patients achieved $0.1 \log$ MAR or better UCDVA, UCIVA, and UCNVA, respectively (Figure 2B). Mean monocular distance and uncorrected VAs at distance, intermediate, and near were $\leq 0.1 \log$ MAR in first and second eyes (Online Table 1).

\section{Defocus Curve}

Binocular defocus testing was consistent with the VA results. TFNT00 maintained a mean VA of $0.1 \log$ MAR $(20 / 25$ Snellen) or better at the defocus range of $+0.5 \mathrm{D}$ to $-2.5 \mathrm{D}(200 \mathrm{~cm}$ to $40 \mathrm{~cm})$ (Figure $3 \mathrm{~A})$, indicating that TFNT00 provides better than functional vision across a full
Table 2 Descriptive Statistics for Photopic Binocular VAs at 3 Months (logMAR) (All-Implanted Analysis Set)

\begin{tabular}{|l|l|l|l|}
\hline VA & N & Mean \pm SD & $95 \%$ Cl \\
\hline \multicolumn{3}{|l|}{ Distance-corrected VAs } \\
\hline BCDVA & 67 & $-0.052 \pm 0.0933$ & -0.074 to -0.029 \\
DCIVA & 66 & $0.039 \pm 0.1149$ & 0.011 to 0.067 \\
DCNVA & 66 & $0.061 \pm 0.1090$ & 0.034 to 0.087 \\
\hline Uncorrected VAs \\
\hline UCDVA & 67 & $0.011 \pm 0.1083$ & -0.015 to 0.038 \\
UCIVA & 66 & $0.055 \pm 0.1024$ & 0.030 to 0.081 \\
UCNVA & 66 & $0.092 \pm 0.1273$ & 0.061 to 0.124 \\
\hline
\end{tabular}

Note: VA outcomes include a patient with a macular hole adverse event. Abbreviations: $\mathrm{BCDVA}$, best-corrected distance visual acuity; $\mathrm{Cl}$, confidence interval; DCIVA, distance-corrected intermediate visual acuity; DCNVA, distance-corrected near visual acuity; $\mathrm{N}$, number of patients in the treatment group; $\mathrm{SD}$, standard deviation; UCDVA, uncorrected distance visual acuity; UCIVA, uncorrected intermediate visual acuity; UCNVA, uncorrected near visual acuity; VA, visual acuity.

range of defocus. Additionally, this continuous range of vision was observed for all pupil sizes $(\sim 0.1 \log$ MAR or better) (Figure 3B).

\section{Refractive Outcomes}

At Month 3, the mean manifest refraction spherical equivalent was approximately $-0.1 \mathrm{D}$ for first and second eyes (Online Table 2). The majority ( $\geq 94 \%$ ) of first and second eyes were within $0.5 \mathrm{D}$ or less of the target refractive error at Month 3 (Online Table 2), representing the good refractive predictability of TFNT00, because the target refraction was emmetropia ( $\pm 0.5 \mathrm{D})$.

\section{Patient-Reported Outcomes}

The large majority of patients (66/67 patients, 98.5\%) were "satisfied" or "very satisfied" with their near, intermediate, and distance vision at Month 3, and $\geq 94 \%$ of patients reported spectacle independence for tasks at all distances (Figure 4A and $\mathrm{B}$ ). The subjective symptom questionnaire-assessed frequency of halo visual disturbances was low at Month 3; halos were reported "none of the time" to "only some of the time" in $86.6 \%$ of patients (Figure 4C) and only 1 patient reported halos as "severe" (Figure 4D). Additionally, 88.6\% of patients reported no difficulty driving at night (data not shown), and all but one individual were either "satisfied" or "very satisfied" with their surgery results (data not shown).

\section{Safety Outcomes \\ Adverse Events}

The most common ocular AEs were PCO (4 events, 5.5\%) and macular fibrosis ( 3 events, $4.1 \%$ ) in the first eye and 


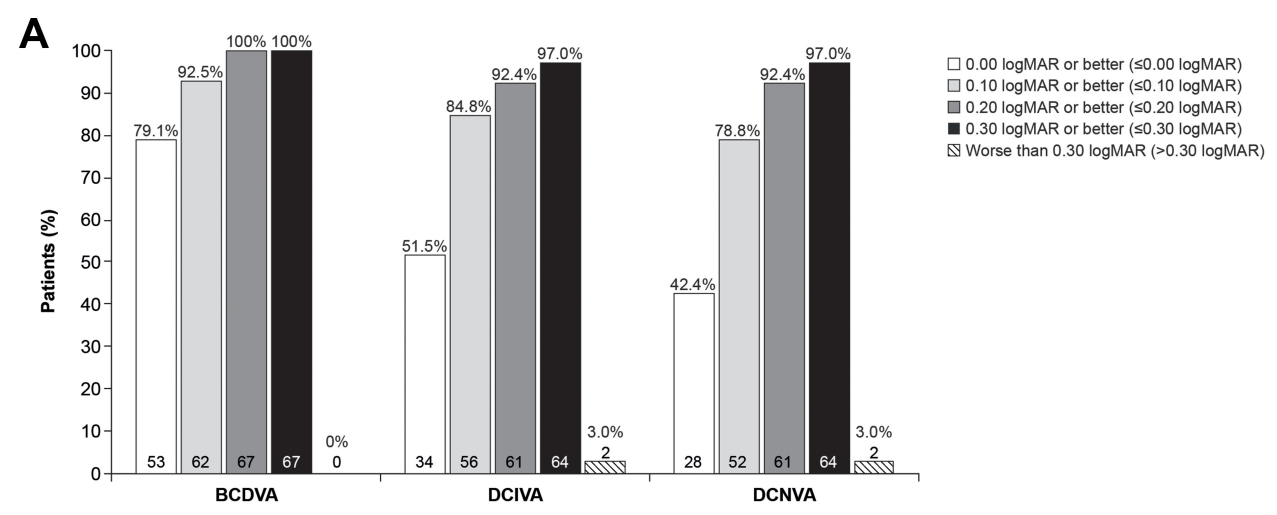

\section{B}

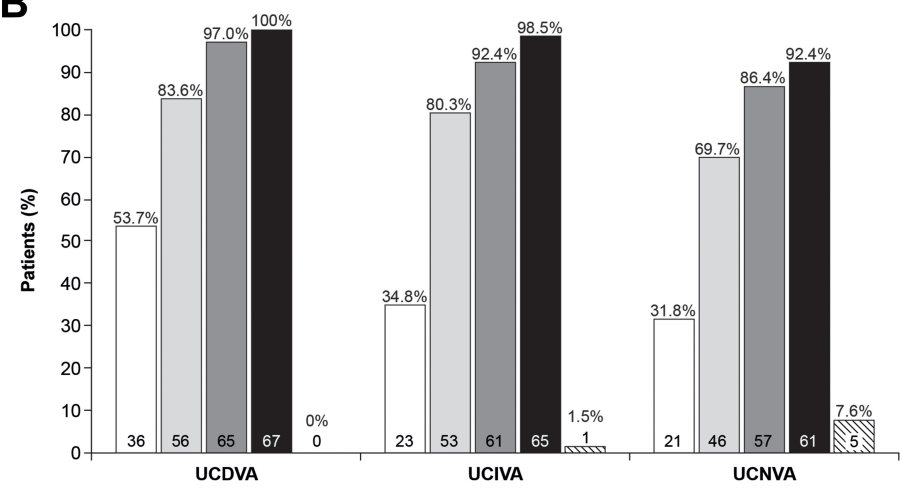

Figure 2 Categorical statistics for photopic binocular (A) distance-corrected and (B) uncorrected VAs at 3 months (logMAR) (all-implanted analysis set). Abbreviations: BCDVA, best-corrected distance visual acuity; DCIVA, distance-corrected intermediate visual acuity; DCNVA, distance-corrected near visual acuity; UCDVA, uncorrected distance visual acuity; UCIVA, uncorrected intermediate visual acuity; UCNVA, uncorrected near visual acuity; VA, visual acuity.

PCO (2 events, 2.9\%) in the second eye (Table 3), although no participants discontinued due to AEs. No eyes underwent Nd:YAG laser posterior capsulotomy during the study (Table 3); however, subjective assessment indicated that of the 6 events coded to PCO, three first eyes and one second eye of 3 patients had clinically significant PCO by the end of the study, of which two first eyes were assessed to require neodymium-doped: yttrium aluminum garnet (Nd:YAG) laser treatment. Of these four eyes with clinically significant PCO, two eyes were described to have eccentric PCO or capsular plaques within 2 weeks of surgery and the PCO in the other two eyes of the same patient was described as capsular folds. The macular fibrosis first eye events included inner retina cystic spaces, internal limiting membrane wrinkling and epiretinal membrane events. One serious ocular AE of macular hole was reported, although this was assessed as unrelated to the IOL; the patient's UCDVA in the right eye was $0.34 \log$ MAR and BCDVA was $0.28 \log$ MAR, which indicate reduced VA. One adverse device event of mild blurred vision was reported during the study. No patients required SSI (Table 3). Additionally, no device deficiencies were reported during the study (data not shown).

\section{Contrast Sensitivity}

Mean mesopic binocular contrast sensitivity with and without glare at 3 months was $>1.5 \log$ units at spatial frequencies of 1.5-6 cycles per degree (cpd), and the values were within the range set for the measuring device. $^{35}$ As expected, only slight reductions were observed with glare as a function of spatial frequency (Figure 5).

\section{Discussion}

Unlike traditional multifocal IOLs, which provide good near vision but may not function effectively at intermediate distances, TFNT00 is functionally a trifocal IOL that provides a continuous range of vision from near to intermediate to distance. TFNT00 is based on non-sequential diffractive optics, in which light has been redistributed to create a trifocal with an enhanced distance power, and $+2.17 \mathrm{D}$ intermediate $(60 \mathrm{~cm})$ and $+3.25 \mathrm{D}$ near $(40 \mathrm{~cm})$ add powers. ${ }^{14,16,18}$ Optimum visual quality at intermediate distance 

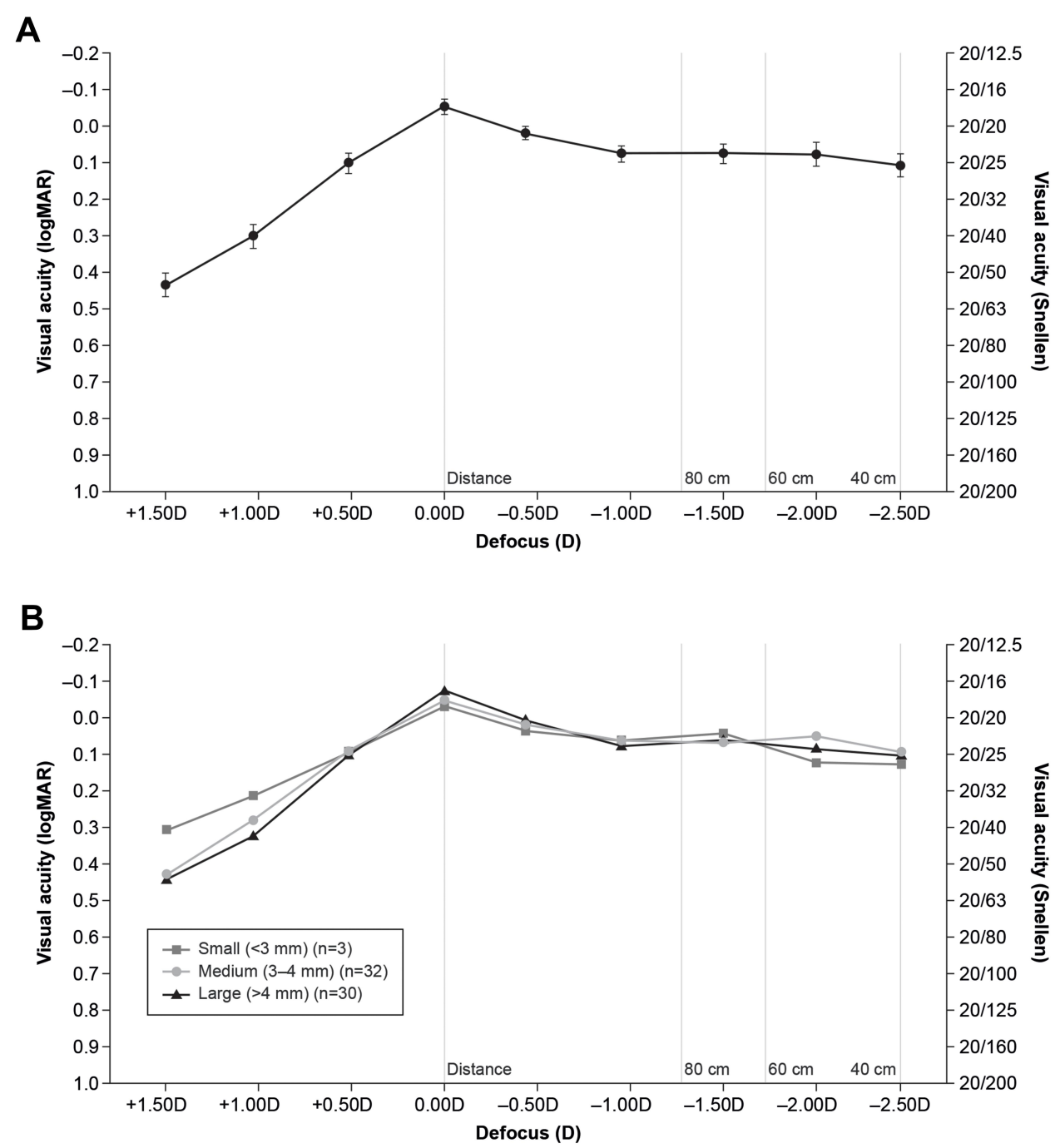

Figure 3 (A) Mean binocular defocus curve with 95\% confidence intervals at 3 months (logMAR); (B) by postoperative pupil size category (best-case analysis set).

is crucial to performing many normal daily activities (eg, use of a computer, tablet, laptop, personal computer, mobile phone). ${ }^{18}$ Although other trifocal IOLs have an intermediate focal point of $80 \mathrm{~cm},{ }^{16}$ TFNT00 targets an intermediate focal point of $60 \mathrm{~cm}$ (relaxed arm's length), which is a distance commonly associated with a more natural and comfortable distance to perform routine daily activities. In contrast, $80 \mathrm{~cm}$ is the approximate arm length of a person $\sim 205 \mathrm{~cm}$ ( 6 feet 8 inches) tall and thus represents a distance further away for the vast majority of patients to reach comfortably. This is of particular significance for Indian patients, for whom average male and female arm length is $\sim 73 \mathrm{~cm}$ and $\sim 65 \mathrm{~cm},{ }^{36}$ and average height is $\sim 163 \mathrm{~cm}$ and $\sim 151 \mathrm{~cm},{ }^{36-38}$ respectively. Furthermore, a viewing distance of $\sim 50-63 \mathrm{~cm}$ (20-25 inches) is recommended while performing tasks using digital screens. ${ }^{15,19,39,40}$
The current study assessed the effectiveness of TFNT00 in providing this continuous range of vision. In line with previous studies, ${ }^{14,18,24,25,27,28,41}$ TFNT00 exhibited a high level of distance, intermediate, and near VA. Mean binocular and monocular distance-corrected and uncorrected VAs of $0.1 \log$ MAR or better were achieved at distance $(4 \mathrm{~m})$, intermediate $(60 \mathrm{~cm})$, and near $(40 \mathrm{~cm})$. Overall, $\geq 70 \%$ of patients achieved binocular $0.1 \log$ MAR vision or better across all distances. VA results were supported by the outcome of the binocular defocus curve for TFNT00, which showed that the lens provided consistently excellent vision of approximately $0.1 \log$ MAR (approximately 20/25 Snellen) or better between +0.50 and $-2.50 \mathrm{D}$, or from distance to near. In the range of intermediate vision (between $60 \mathrm{~cm}$ and $80 \mathrm{~cm}$ ), the defocus curve was flat, suggesting stable intermediate vision is 

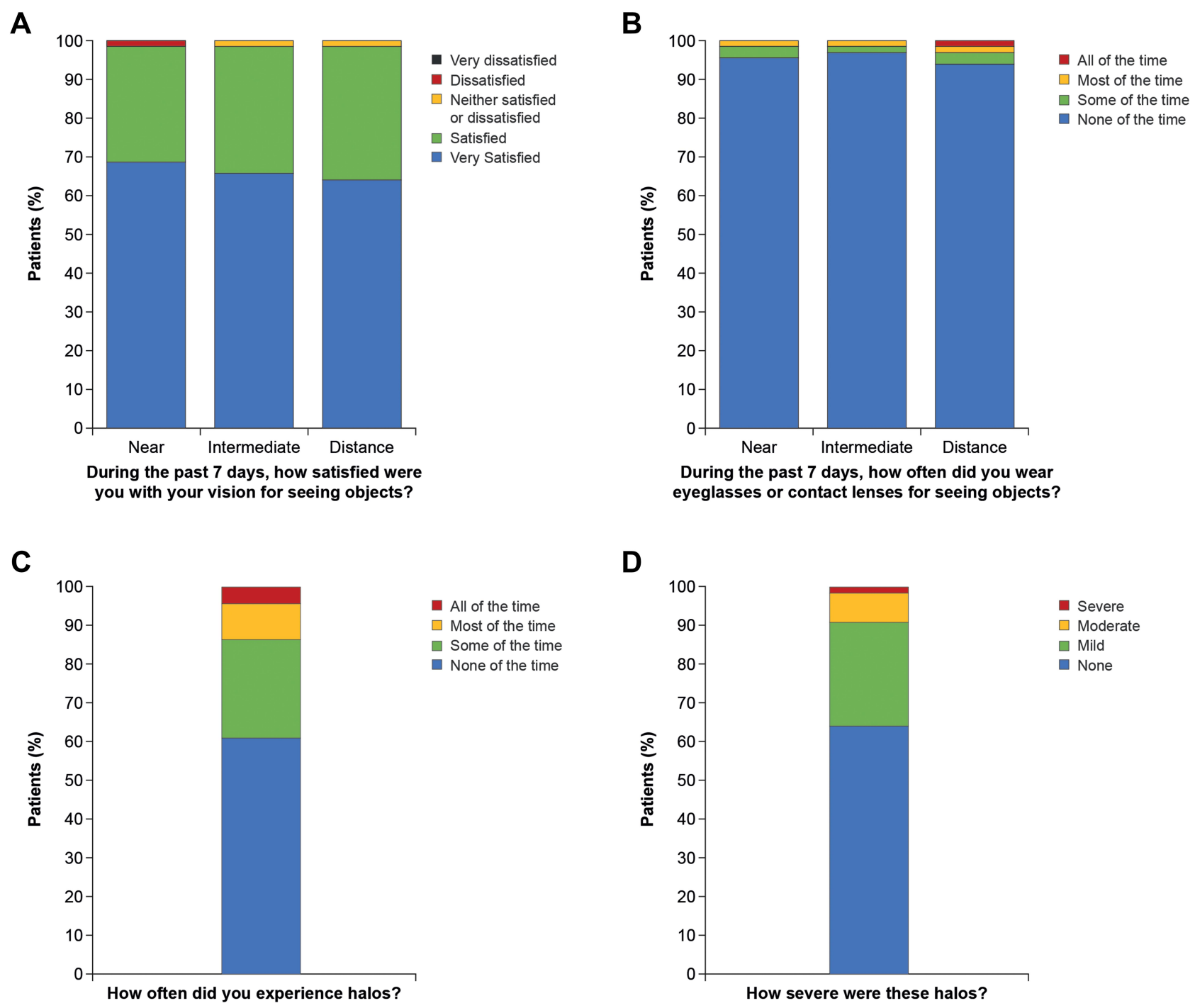

Figure 4 Subjective symptom questionnaire at 3 months (all-implanted analysis set). Patients were asked (A) "During the past 7 days, how satisfied are you with your vision for seeing objects?"; (B) “During the past 7 days, how often do you wear eyeglasses or contact lenses for seeing objects?”; (C) "How often did you experience halos?"; and (D) "How severe were these halos?".

provided by TFNT00. Overall, this study shows that the Indian population had similar visual outcomes of $\leq 0.1$ $\log$ MAR at all distances to those of patients in other comparative and non-comparative studies who received TFNT00 with a 3-month follow-up period. ${ }^{14,27,41-44}$ Patient satisfaction with the TFNT00 visual outcomes was reflected in the subjective symptom questionnaire results, with 66 out of 67 patients $(98.5 \%)$ being "satisfied" or "very satisfied" with their near, intermediate, and distance vision. In this study, TFNT00 recipients could engage in activities that required a range of vision while being spectacle-free.

Previous clinical comparative investigations have demonstrated improved intermediate $(60 \mathrm{~cm})$ and near visual outcomes for TFNT00, compared to earliergeneration trifocal IOLs. TFNT00 showed improved VA at $60 \mathrm{~cm}$ versus FineVision Micro F (PhysIOL SA) trifocal IOL $(\mathrm{p}<0.05) .{ }^{18}$ Furthermore, VA at the preferred reading distance $(\sim 42 \mathrm{~cm})$ was $0.07 \pm 0.07$ and $0.11 \pm 0.08$ $\operatorname{logMAR}$ for TFNT00 and Micro F, respectively $(p=0.04) .{ }^{18}$ Defocus curve data reported by de Carneros Llorente et $\mathrm{al}^{45}$ for TFNT00, Micro F, and AT LISA 839MP (Carl Zeiss Meditec) trifocal IOLs demonstrated significantly improved VA for patients who received TFNT00 compared with recipients of the other two trifocal IOLs at defocus levels of $-1.50 \mathrm{D}$ and $-2.00 \mathrm{D}(\mathrm{p} \leq 0.04)$. In a large multicenter trial, binocular UCIVA and UCNVA were better for TFNT00 recipients compared with 839MP 
Table 3 Adverse Events and Secondary Surgical Interventions (Safety Analysis Set)

\begin{tabular}{|c|c|c|c|c|}
\hline \multirow[b]{2}{*}{ Preferred term } & \multicolumn{2}{|c|}{ First Eye $(n=73)$} & \multicolumn{2}{|c|}{ Second Eye $(n=68)$} \\
\hline & n (\%) & $\mathbf{E}$ & n (\%) & $\mathbf{E}$ \\
\hline Posterior capsule opacification & $4^{\mathrm{a}}(5.5)$ & 4 & $2^{\mathrm{a}}(2.9)$ & 2 \\
\hline Macular fibrosis & $3(4.1)$ & 3 & $\mathrm{I}(\mathrm{I} .5)$ & I \\
\hline Punctate keratitis & $\mathrm{I}(\mathrm{l} .4)$ & 2 & 0 & 0 \\
\hline Glare & $\mathrm{I}(\mathrm{l} .4)$ & 1 & $\mathrm{I}(\mathrm{I} .5)$ & I \\
\hline Macular hole ${ }^{b}$ & $\mathrm{I}(\mathrm{l} .4)$ & I & 0 & 0 \\
\hline Ocular hyperemia & I (I.4) & I & 0 & 0 \\
\hline Retinal injury & $\mathrm{I}(\mathrm{l} .4)$ & I & 0 & 0 \\
\hline Retinal pigment epitheliopathy & 0 & 0 & $\mathrm{I}(\mathrm{I} .5)$ & I \\
\hline Vision blurred & I (I.4) & 1 & 0 & 0 \\
\hline Vitreous detachment & $\mathrm{I}(\mathrm{I} .4)$ & 1 & $\mathrm{I}(\mathrm{l} .5)$ & I \\
\hline \multicolumn{5}{|l|}{ Ocular adverse device effects } \\
\hline Vision blurred & I (I.4) & 1 & 0 & 0 \\
\hline & \multicolumn{2}{|c|}{ First Eye, $n(\%)$} & \multicolumn{2}{|c|}{ Second Eye, n (\%) } \\
\hline Secondary surgical interventions & \multicolumn{2}{|l|}{0} & \multicolumn{2}{|l|}{0} \\
\hline \multicolumn{5}{|l|}{ Subjective PCO or posterior capsulotomy } \\
\hline None & \multicolumn{2}{|l|}{$69(94.5)$} & \multicolumn{2}{|l|}{$66(97.1)$} \\
\hline Clinically nonsignificant & \multicolumn{2}{|l|}{ I (I.4) } & \multicolumn{2}{|l|}{ I (I.5) } \\
\hline Clinically significant & \multicolumn{2}{|l|}{$\mathrm{I}(\mathrm{l} .4)$} & \multicolumn{2}{|l|}{ I ( $(1.5)$} \\
\hline Clinically significant requiring $\mathrm{Nd}$ :YAG treatment & \multicolumn{2}{|l|}{$2(2.7)$} & \multicolumn{2}{|l|}{0} \\
\hline Posterior capsulotomy & \multicolumn{2}{|l|}{0} & \multicolumn{2}{|l|}{0} \\
\hline
\end{tabular}

Notes: ${ }^{a}$ Two first eyes and one second eye had events described as posterior capsular plaques. 'berious adverse device effect.

Abbreviations: E, event; Nd:YAG, neodymium-doped yttrium aluminum garnet; PCO, posterior capsular opacity.

recipients ( $\mathrm{p}=0.002$ and $\mathrm{p}=0.003$, respectively) 6 months after IOL implantation. ${ }^{23}$ Additionally, defocus curve VA was improved with TFNT00 versus $839 \mathrm{MP}$ at $1.00 \mathrm{D}$, $-1.00 \mathrm{D},-1.50 \mathrm{D},-2.00 \mathrm{D}$, and $-2.50 \mathrm{D}{ }^{46}$ In line with these findings, in a non-comparative study, Kohnen et $\mathrm{al}^{14}$ found that TFNT00 provided better VA results between $50 \mathrm{~cm}$ and $60 \mathrm{~cm}$ than previous outcomes with other trifocal IOLs. However, additional head-to-head studies would be needed to demonstrate such a benefit of TFNT00 in Indian patients.

Previous studies demonstrated a good safety profile for TFNT00, which was further supported by the results of this study. ${ }^{47,48}$ No patients discontinued the study as a result of an AE, and no SSIs were reported. Furthermore, no eyes underwent Nd:YAG laser posterior capsulotomy during the study; however, three first eyes and one second eye of 3 patients displayed clinically significant PCO by the end of the study, of which two first eyes were assessed to require $\mathrm{Nd}$ :YAG laser posterior capsulotomy. Of these four eyes with clinically significant PCO, two eyes were described to have eccentric PCO or capsular plaques within 2 weeks of surgery and the PCO in the other two eyes of the same patient was described as capsular folds. The rates of PCO were higher than those reported in previous comparative 3-month studies of the same lens, ${ }^{42,43}$ although they were lower than or similar to those reported in comparative and non-comparative 6-month studies. ${ }^{23,28,46,49}$ Importantly, PCO did not affect patient satisfaction; all but one patient in the study indicated that they were "satisfied" or "very satisfied" with their cataract surgery results (the other patient was "neither satisfied nor dissatisfied").

Diminished contrast sensitivity has long been a limitation of some multifocal IOL designs, because light from the out-of-focus image may reduce the sharpness of the in-focus image. ${ }^{1,25,50}$ This effect has been described at multiple spatial frequencies, with and/or withoutglare. ${ }^{1,3,5,50}$ In this study, mean mesopic binocular contrast sensitivity with and without glare at 3 months was $>1.5 \log$ units at spatial frequencies of 1.5 to $6 \mathrm{cpd}$ and within the range set for the measuring device for normal patients of a similar age. ${ }^{35}$ As expected, only slight 


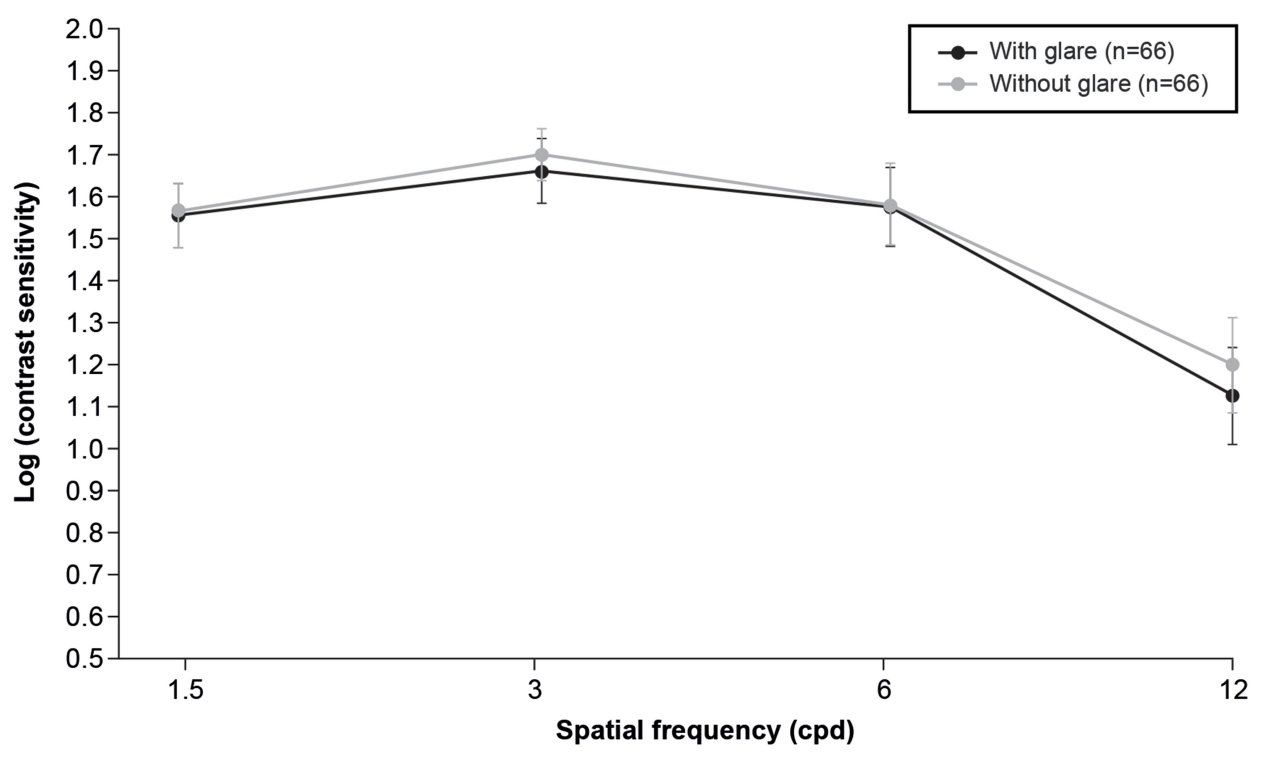

Figure 5 Mean binocular mesopic contrast sensitivity with or without glare (log units) (best-case analysis set).

clinically insignificant reductions were observed with glare as a function of spatial frequency, representing good quality of vision with TFNT00. These results are in agreement with previous studies that have demonstrated good contrast sensitivity outcomes in TFNT00 recipients. ${ }^{25,51,52}$ These contrast sensitivity results may be attributable to the TFNT00 IOL design; the higher energy utilization of TFNT00 (up to $88 \%$ ) than other trifocals (85-86\%), and a smaller diffractive zone $(4.5 \mathrm{~mm}$ and $6.0 \mathrm{~mm}$, respectively), are suggested to result in functional vision that is less dependent on pupil size or lighting conditions and provides better contrast sensitivity. ${ }^{13-15,25,49}$ These design features could also explain the increased proportion of patients who reported no difficulty driving at night in this study $(88.6 \%)$.

Increased incidence of visual disturbances, which consist of photic phenomena such as halos, is a common outcome of diffractive multifocalIOLs. ${ }^{2,53}$ In this study, the majority of TFNT00 recipients (86.6\%) experienced halos from "none of the time" to only "some of the time" postoperatively; additionally, only one patient reported their halos as severe. Furthermore, no SSIs were required because of visual disturbances. The low reported frequency and severity of visual disturbances may be due to the design of the TFNT00 lens. ${ }^{18}$ In the current study, visual disturbances were assessed using a subjective symptom questionnaire, consisting of items derived from the APPLES ${ }^{32}$ questionnaire. Rasch-based patient-reported outcome measures questionnaires, however, may better capture the subjective patient experience and could facilitate crossstudy comparisons. ${ }^{31}$ Further studies would be needed to assess the perception of additional visual disturbances associated with diffractive multifocal IOLs, such as glare and starbursts, which would help further characterize the quality of vision following TFNT00 implantation. ${ }^{54}$ Additionally, objective testing methods using straylight meters, halometry, or computer-based simulators could be used to capture supportive quantitative metrics. ${ }^{55}$

Limitations of the present study include a relatively short follow-up period of 3 months and the lack of a comparator IOL. Future trials should evaluate the longterm outcomes and patient satisfaction with TFNT00 in the Indian population compared with other multifocal lens options for the correction of presbyopia. An additional consideration in this study is that non-toric TFNT00 IOLs were implanted in patients displaying up to $1 \mathrm{D}$ of astigmatism, which may explain the slightly low values for uncorrected VAs, especially for patients with against-therule astigmatism. For this patient population, the toric TFNT00 IOL may provide better VA outcomes, although studies need to be conducted to support this hypothesis.

\section{Conclusion}

This study has demonstrated that TFNT00 provides excellent vision of $0.1 \log$ MAR (20/25) or better across a range of distances, with a favorable safety profile, and high patient satisfaction. Overall, the diffractive trifocal IOL TFNT00 may provide this population with a continuous 
range of vision, resulting in spectacle independence over a range of distance to near tasks.

\section{Abbreviations}

AE, adverse event; APPLES, Assessment of Photic Phenomena and Lens EffectS; BCDVA, best-corrected distance visual acuity; cpd, cycles per degree; D, diopters; DCIVA, distance-corrected intermediate visual acuity; DCNVA, distance-corrected near visual acuity; IOL, intraocular lens; MedDRA, Medical Dictionary for Regulatory Activities; Nd:YAG, neodymium-doped yttrium aluminum garnet; PCO, posterior capsular opacification; SD, standard deviation; SSI, secondary surgical intervention; SILVER, Spectacle Independence Lens Vision Evaluation and Repurchase; UCDVA, uncorrected distance visual acuity; UCIVA, uncorrected intermediate visual acuity; UCNVA, uncorrected near visual acuity; VA, visual acuity.

\section{Data Sharing Statement}

No further data beyond those provided in this manuscript will be shared.

\section{Acknowledgments}

The authors thank Aarti Shah for editorial assistance in the preparation of the manuscript, with funding from Alcon Research LLC.

\section{Author Contributions}

All authors made substantial contributions to the conception and design, acquisition of data, or analysis and interpretation of data; took part in drafting the article or revising it critically for important intellectual content; agreed to submit to the current journal; gave final approval of the version to be published; and agreed to be accountable for all aspects of the work.

\section{Funding}

This work was sponsored by Alcon Research LLC, Fort Worth, Texas. The sponsors participated in the design of the study, data management, data analysis, interpretation of the data, preparation, review, and approval of the manuscript.

\section{Disclosure}

Dr Dandapani Ramamurthy reports company-sponsored prospective multicentric study for ALCON, during the conduct of the study; and consultancy for Alcon, outside the submitted work. Dr Abhay Vasavada reports research grant support from Alcon Laboratories, outside the submitted work. Dr
Arindam Dey is an employee of Alcon (Alcon Laboratories (India) Private Ltd). The authors report no other conflicts of interest in this work.

\section{References}

1. Wang SY, Stem MS, Oren G, Shtein R, Lichter PR. Patient-centered and visual quality outcomes of premium cataract surgery: a systematic review. Eur J Ophthalmol. 2017;27(4):387-401. doi:10.5301/ejo.5000978

2. Javitt J, Brauweiler HP, Jacobi KW, et al. Cataract extraction with multifocal intraocular lens implantation: clinical, functional, and quality-of-life outcomes. Multicenter clinical trial in Germany and Austria. $J$ Cataract Refract Surg. 2000;26(9):1356-1366. doi:10.1016/S0886-3350(00)00636-2

3. Zhao G, Zhang J, Zhou Y, Hu L, Che C, Jiang N. Visual function after monocular implantation of apodized diffractive multifocal or single-piece monofocal intraocular lens randomized prospective comparison. J Cataract Refract Surg. 2010;36(2):282-285. doi:10.1016/j.jcrs.2009.08.037

4. de Silva SR, Evans JR, Kirthi V, Ziaei M, Leyland M. Multifocal versus monofocal intraocular lenses after cataract extraction. Cochrane Database Syst Rev. 2016;12:CD003169. doi:10.1002/ 14651858.CD003169.pub4

5. Vingolo EM, Grenga P, Iacobelli L, Grenga R. Visual acuity and contrast sensitivity: AcrySof ReSTOR apodized diffractive versus AcrySof SA60AT monofocal intraocular lenses. $J$ Cataract Refract Surg. 2007;33(7):1244-1247. doi:10.1016/j.jcrs.2007.03.052

6. Kohnen T, Allen D, Boureau C, et al. European multicenter study of the AcrySof ReSTOR apodized diffractive intraocular lens. Ophthalmology. 2006;113(4):578-584. doi:10.1016/j.ophtha.2005.11.020

7. Cillino S, Casuccio A, Di Pace F, et al. One-year outcomes with new-generation multifocal intraocular lenses. Ophthalmology. 2008;115(9):1508-1516. doi:10.1016/j.ophtha.2008.04.017

8. Zeng M, Liu Y, Liu X, et al. Aberration and contrast sensitivity comparison of aspherical and monofocal and multifocal intraocular lens eyes. Clin Exp Ophthalmol. 2007;35(4):355-360. doi:10.1111/ j.1442-9071.2007.01452.x

9. Alfonso JF, Fernández-Vega L, Amhaz H, Montes-Mico R, Valcarcel B, Ferrer-Blasco T. Visual function after implantation of an aspheric bifocal intraocular lens. $J$ Cataract Refract Surg. 2009;35 (5):885-892. doi:10.1016/j.jcrs.2009.01.014

10. Alfonso JF, Fernández-Vega L, Baamonde MB, Montés-Micó R. Prospective visual evaluation of apodized diffractive intraocular lenses. $J$ Cataract Refract Surg. 2007;33(7):1235-1243. doi:10.1016/j.jcrs.2007.03.034

11. Cochener B, Vryghem J, Rozot P, et al. Clinical outcomes with a trifocal intraocular lens: a multicenter study. J Refract Surg. 2014;30(11):762-768. doi:10.3928/1081597X-20141021-08

12. Mojzis P, Peña-García P, Liehneova I, Ziak P, Alió JL. Outcomes of a new diffractive trifocal intraocular lens. $J$ Cataract Refract Surg. 2014;40(1):60-69. doi:10.1016/j.jcrs.2013.06.025

13. Kohnen T. First implantation of a diffractive quadrafocal (trifocal) intraocular lens. J Cataract Refract Surg. 2015;41(10):2330-2332. doi:10.1016/j.jcrs.2015.11.012

14. Kohnen T, Herzog M, Hemkeppler E, et al. Visual performance of a quadrifocal (trifocal) intraocular lens following removal of the crystalline lens. Am $J$ Ophthalmol. 2017;184:52-62. doi:10.1016/j. ajo.2017.09.016

15. Sudhir RR, Dey A, Bhattacharrya S, Bahulayan A. AcrySof IQ PanOptix intraocular lens versus extended depth of focus intraocular lens and trifocal intraocular lens: a clinical overview. Asia Pac J Ophthalmol (Phila). 2019;8(4):335-349. doi:10.1097/ APO. 0000000000000253 
16. Carson D, Xu Z, Alexander E, Choi M, Zhao Z, Hong X. Optical bench performance of 3 trifocal intraocular lenses. J Cataract Refract Surg. 2016;42(9):1361-1367. doi:10.1016/j.jcrs.2016.06.036

17. Cochener B, Boutillier G, Lamard M, Auberger-Zagnoli C. A comparative evaluation of a new generation of diffractive trifocal and extended depth of focus intraocular lenses. J Refract Surg. 2018;34(8):507-514. doi:10.3928/1081597X-20180530-02

18. Gundersen KG, Potvin R. Trifocal intraocular lenses: a comparison of the visual performance and quality of vision provided by two different lens designs. Clin Ophthalmol. 2017;11:1081-1087. doi:10.2147/ OPTH.S136164

19. American Optometric Association. Computer vision syndrome; 2015. Available from: https://www.aoa.org/patients-and-public/caring-foryour-vision/protecting-your-vision/computer-vision-syndrome. Accessed October 1, 2020.

20. Aravind S, Haripriya A, Sumara Taranum BS. Cataract surgery and intraocular lens manufacturing in India. Curr Opin Ophthalmol. 2008;19(1):60-65. doi:10.1097/ICU.0b013e3282f2aaed

21. Murthy G, Gupta SK, John N, Vashist P. Current status of cataract blindness and vision 2020: the right to sight initiative in India. Indian $J$ Ophthalmol. 2008;56(6):48994. doi:10.4103/03014738.42774

22. Reddy JC, Vaddavalli PK, Sharma N, et al. A new normal with cataract surgery during COVID-19 pandemic. Indian J Ophthalmol. 2020;68(7):1269. doi:10.4103/ijo.IJO 152820

23. Lapid-Gortzak R, Bhatt U, Sanchez JG, et al. Multicenter visual outcomes comparison of 2 trifocal presbyopia-correcting IOLs: 6-month postoperative results. J Cataract Refract Surg. 2020;46 (11):1534-1542. doi:10.1097/j.jcrs.0000000000000274

24. Lawless M, Hodge C, Reich J, et al. Visual and refractive outcomes following implantation of a new trifocal intraocular lens. Eye Vis (Lond). 2017;4(1):10. doi:10.1186/s40662-017-0076-8

25. García-Pérez JL, Gros-Otero J, Sánchez-Ramos C, Blázquez V, Contreras I. Short term visual outcomes of a new trifocal intraocular lens. BMC Ophthalmol. 2017;17(1):72. doi:10.1186/s12886-0170462-y

26. Alfonso JF, Fernández-Vega-Cueto L, Fernández-Vega L, Montés-Micó R. Visual function after implantation of a presbyopia-correcting trifocal intraocular lens. Ophthalmic Res. 2020;63(2):152-164. doi:10.1159/000500834

27. Rementería-Capelo LA, Contreras I, García-Pérez JL, Blázquez V, Ruiz-Alcocer J. Visual quality and patient satisfaction with a trifocal intraocular lens and its new toric version. J Cataract Refract Surg. 2019;45(11):1584-1590. doi:10.1016/j.jcrs.2019.06.014

28. Donmez O, Asena BS, Kaskaloglu M, Akova YA. Patients satisfaction and clinical outcomes of binocular implantation of a new trifocal intraocular lens. Int Ophthalmol. 2020;40(5):1069-1075. doi:10.1007/s10792-020-01390-9

29. Barrett GD. An improved universal theoretical formula for intraocular lens power prediction. J Cataract Refract Surg. 1993;19 (6):713-720. doi:10.1016/S0886-3350(13)80339-2

30. Alcon Research LLC. Clinical investigation of AcrySof ${ }^{\circledR}$ IQ $\operatorname{ReSTOR}^{\circledR}+2.5$ D multifocal intraocular lens (IOL) Model SN6AD2 [SV25T0]. Available from: https://clinicaltrials.gov/ct2/ show/NCT01510717. Accessed July 2, 2020.

31. Grzybowski A, Kanclerz P, Muzyka-Wozniak M. Methods for evaluating quality of life and vision in patients undergoing lens refractive surgery. Graefes Arch Clin Exp Ophthalmol. 2019;257 (6):1091-1099. doi:10.1007/s00417-019-04270-w

32. Maxwell A, Holland E, Cibik L, et al. Clinical and patient-reported outcomes of bilateral implantation of a +2.5 diopter multifocal intraocular lens. J Cataract Refract Surg. 2017;43(1):29-41. doi:10.1016/j. jcrs.2016.10.026

33. Alcon Research LLC. Acrysof ${ }^{\circledR}$ ReSTOR $^{\circledR}$ aspheric +3.0 D add power intraocular lens (IOL). Available from: https://clinicaltrials. gov/ct2/show/NCT00684138. Accessed June 1, 2020.
34. Alcon Research LLC. AcrySof ${ }^{\circledR} I Q$ ReSTOR ${ }^{\circledR}+2.5$ D Multifocal Intraocular Lens (IOL) (Model SV25T0) Product Information. 2015.

35. VectorVision Ocular Health. Normal contrast sensitivity values for CSV-1000; 2020. Available from: http://www.vectorvision.com/ csv1000-norms/. Accessed May, 2020.

36. Kamal R, Yadav PK. Estimation of stature from different anthropometric measurements in Kori population of North India. Egypt J Forensic Sci. 2016;6(4):468-477. doi:10.1016/j.ejfs.2016.12.001

37. Kim R, Pathak PK, Tripathi N, Subramanian S. Heterogeneity in adult anthropometry by socioeconomic factors: indian national family health survey 2006 and 2016. Eur J Clin Nutr. 2020;74(6):953-960. doi:10.1038/s41430-019-0511-0

38. Goswami AK, Kalaivani M, Gupta SK, Nongkynrih B, Pandav CS. Relationship between height and arm span of elderly persons in an urban colony of New Delhi. Indian J Public Health. 2018;62 (2):159-162. doi:10.4103/ijph.IJPH_378_16

39. Charness N, Dijkstra K, Jastrzembski $\bar{T}$, Weaver S, Champion M. Monitor viewing distance for younger and older workers. Proceedings of the Human Factors and Ergonomics Society. 3. New York, NY: 52nd Human Factors and Ergonomics Society Annual Meeting; 2008:1614-1617.

40. Turgut B. Ocular ergonomics for the computer vision syndrome. J Eye Vis. 2018;1(1):2.

41. Mencucci R, Favuzza E, Caporossi O, Savastano A, Rizzo S. Comparative analysis of visual outcomes, reading skills, contrast sensitivity, and patient satisfaction with two models of trifocal diffractive intraocular lenses and an extended range of vision intraocular lens. Graefes Arch Clin Exp Ophthalmol. 2018;256(10):1913-1922. doi:10.1007/s00417-018-4052-3

42. Böhm M, Hemkeppler E, Herzog M, et al. Comparison of a panfocal and trifocal diffractive intraocular lens after femtosecond laser-assisted lens surgery. J Cataract Refract Surg. 2018;44 (12):1454-1462. doi:10.1016/j.jcrs.2018.07.060

43. Böhm M, Petermann K, Hemkeppler E, Kohnen T. Defocus curves of 4 presbyopia-correcting IOL designs: diffractive panfocal, diffractive trifocal, segmental refractive, and extended-depth-of-focus. J Cataract Refract Surg. 2019;45(11):1625-1636. doi:10.1016/j.jcrs.2019.07.014

44. Ribeiro F, Ferreira TB. Comparison of clinical outcomes of 3 trifocal IOLs. J Cataract Refract Surg. 2020;46(9):1247-1252. doi:10.1097/j. jcrs.0000000000000118

45. de Carneros-llorente AM, de Carneros AM, de Carneros-llorente PM, Jiménez-Alfaro I. Comparison of visual quality and subjective outcomes among 3 trifocal intraocular lenses and 1 bifocal intraocular lens. J Cataract Refract Surg. 2019;45(5):587-594. doi:10.1016/j. jers.2018.12.005

46. Asena BS. Visual and refractive outcomes, spectacle independence, and visual disturbances after cataract or refractive lens exchange surgery: comparison of 2 trifocal intraocular lenses. J Cataract Refract Surg. 2019;45(11):1539-1546. doi:10.1016/j.jcrs.2019.06.005

47. Alcon Research LLC. Investigation of AcrySof ${ }^{\circledR}$ IQ PanOptix ${ }^{\mathrm{TM}}$ presbyopia-correcting intraocular lens (IOL) model TFNT00; 2018. Available from: https:/clinicaltrials.gov/ct2/show/NCT02529488. Accessed July 1, 2020.

48. Alcon Research LLC. AcrySof ${ }^{\circledR}$ IQ PanOptix ${ }^{\circledR}$ Trifocal IOL model TFNT00 directions for use; 2019. Available from: https://www.access data.fda.gov/cdrh_docs/pdf4/P040020S087D.pdf. Accessed November $11,2020$.

49. Modi S, Lehmann R, Maxwell A, et al. Visual and patient-reported outcomes of a diffractive trifocal intraocular lens compared with those of a monofocal intraocular lens. Ophthalmology. 2020. doi:10.1016/j.ophtha.2020.07.015

50. Cao K, Friedman DS, Jin S, et al. Multifocal versus monofocal intraocular lenses for age-related cataract patients: a system review and meta-analysis based on randomized controlled trials. Surv Ophthalmol. 2019;64(5):647-658. doi:10.1016/j. survophthal.2019.02.012 
51. Vilar C, Hida WT, de Medeiros AL, et al. Comparison between bilateral implantation of a trifocal intraocular lens and blended implantation of two bifocal intraocular lenses. Clin Ophthalmol. 2017;11:1393-1397. doi:10.2147/OPTH.S139909

52. Alió JL, Plaza-Puche AB, Alio Del Barrio JL, et al. Clinical outcomes with a diffractive trifocal intraocular lens. Eur J Ophthalmol. 2018;28(4):419-424. doi:10.1177/1120672118762231

53. Escandón-García S, Ribeiro F, McAlinden C, Queirós A, GonzálezMéijome JM. Through-focus vision performance and light disturbances of 3 new intraocular lenses for presbyopia correction. J Ophthalmol. 2018;2018:1-8. doi:10.1155/2018/6165493
54. Almulhim AK, Alarfaj KM, Altaisan AA, Alromaih AZ, Aldawod RA. Visual outcomes and patient satisfaction after bilateral implantation of a new trifocal diffractive intraocular lens. Saudi J Ophthalmol. 2018;32(4):310-317. doi:10.1016/j.sjopt.2018.08.004

55. Kohnen T, Suryakumar R. Measures of visual disturbance in patients receiving extended depth-of-focus or trifocal intraocular lenses. J Cataract Refract Surg. 2020. doi:10.1097/j.jcrs.0000000000000364

\section{Publish your work in this journal}

Clinical Ophthalmology is an international, peer-reviewed journal covering all subspecialties within ophthalmology. Key topics include: Optometry; Visual science; Pharmacology and drug therapy in eye diseases; Basic Sciences; Primary and Secondary eye care; Patient Safety and Quality of Care Improvements. This journal is indexed on PubMed

Submit your manuscript here: https://www.dovepress.com/clinical-ophthalmology-journal
Central and CAS, and is the official journal of The Society of Clinical Ophthalmology (SCO). The manuscript management system is completely online and includes a very quick and fair peer-review system, which is all easy to use. Visit http://www.dovepress.com/ testimonials.php to read real quotes from published authors. 